\title{
REMINERALIZATION EFFECT OF FLUORIDE VARNISH CONTAINING CASEIN PHOSPHOPEPTIDE AMORPHOUS CALCIUM PHOSPHATE ON CARIES-LIKE LESIONS IN PRIMARY TEETH (IN VITRO STUDY)
}

\author{
Nehal R. Salman ${ }^{1} B D S$, Magda M. El-Tekeya ${ }^{2} h h D$, Niveen Bakry²$P h D$, Samia Soliman ${ }^{3} P h D$
}

\begin{abstract}
INTRODUCTION: Fluoride containing casein phosphopeptide amorphous calcium phosphate (CPP-ACP) varnishes are now available as (MI Varnish). It has an effect on the remineralization process of demineralized enamel, since it has the highest release of calcium and fluoride ions.

OBJECTIVES: To study the remineralizing effect of fluoride varnish containing casein phosphopeptide amorphous calcium phosphate (MI varnish) on the remineralization of caries-like lesions in primary teeth compared to sodium fluoride varnish.

MATERIALS AND METHODS: Twenty-four freshly extracted primary maxillary incisors with standardized 4x4 windows were immersed in demineralizing solution for four days. Teeth were divided into two groups, group I ( $\mathrm{n}=12$ teeth); MI varnish and group II ( $\mathrm{n=12}$ teeth); Prevident varnish. They were sectioned into two halves in a buccolingual direction (48 specimens). One half was treated with the remineralizing agent and the other half remained untreated and served as its control. Specimens were assigned into subgroup I A (MI varnish) $n=12$ specimens, subgroup I B (untreated) $n=12$ specimens, subgroup II A (Prevident varnish) $n=12$ specimens and subgroup II B (untreated) n=12 specimens. Specimens were subjected to $\mathrm{pH}$ cycling for ten days. The specimens were evaluated quantitatively using energy dispersive $\mathrm{x}$-ray spectrometer (EDX).

RESULTS: MI varnish treated specimens (subgroup I A) showed significant high mean $\mathrm{Ca}, \mathrm{Ca} / \mathrm{P}$ ratio than the untreated specimens. Also, Prevident varnish treated specimens showed significant high mean $\mathrm{Ca}, \mathrm{Ca} / \mathrm{P}$ ratio than the untreated specimens. Median percent change of $\mathrm{Ca} / \mathrm{P}$ ratio of MI varnish treated specimens was significantly higher than Prevident varnish treated specimens.

CONCLUSIONS: Fluoride varnish containing CPP-ACP has a higher remineralization potential of the caries-like lesion in primary teeth in comparison to sodium fluoride varnish.

KEYWORDS: (MI varnish), casein phosphopeptide amorphous calcium phosphate (CPP-ACP), remineralization, fluoride varnish, primary teeth, energy dispersive $\mathrm{x}$-ray spectrometer.
\end{abstract}

1-Instructor, Department of Pediatric Dentistry, Faculty of Dentistry, Pharos University, Egypt.

2-Professor of Pediatric Dentistry, Department of Pediatric Dentistry and Dental Public Health, Faculty of Dentistry, Alexandria University, Egypt.

3-Professor of Oral Biology, Department of Oral Biology, Faculty of Dentistry, Alexandria University, Egypt.

Corresponding author:

E-mail:nrsalman@outlook.com

\section{INTRODUCTION}

Demineralization (mineral loss) and remineralization (mineral gain) is a dynamic physicochemical process. When oral bacteria form a biofilm on the enamel surface and get exposed to fermentable dietary carbohydrates, this biofilm becomes undersaturated with respect to the enamel mineral, and demineralization occurs (1). Remineralization is defined as the process whereby calcium and phosphate ions are supplied from a source external to tooth to promote ion deposition into crystal voids in demineralized enamel. The optimal goal of minimal invasive dental caries management is to prevent the incipient lesion by inhibiting the demineralization process, preventing any further mineral loss and enhancing the remineralization process (2).

Fluoride has an important role in remineralization and repair of incipient lesions (3). Fluoride ions promote the formation of fluorapatite in enamel in the presence of calcium and phosphate ions produced during enamel demineralization by plaque bacterial organic acids (4). There are microscopic porosities on the surface of the enamel, which enable fluoride deposition (5). Consequently, steady release of fluoride into the dental plaque can occur (6). Fluoride varnishes contain 5\% sodium fluoride (approximately 20 times the fluoride concentration of conventional dentifrices), which aids in the formation of long lasting intraoral fluoride reservoirs (7).

Calcium phosphate remineralizing agents have been developed to manage non-cavitated caries lesions noninvasively through remineralization (6). Peptide-based therapeutic approaches to prevent dental caries have resulted in a commercialized product marketed as (Recaldent ${ }^{\mathrm{TM}}$ ), which contains casein phosphopeptides (CPP) derived from milk caseins that bind with amorphous calcium phosphate (ACP) to form casein phosphopeptideamorphous calcium phosphate (CPP-ACP) (8). Llena et al (9) have reported that CPP-ACP acts as calcium and phosphate reservoir, in which ACP is stabilized by CPP. CPP-ACP plays a main role by suppressing demineralization and enhancing remineralization of enamel subsurface lesions in situ caries models (10). Heikal (11) concluded that fluoride incorporated into CPP-ACP paste (CPP-ACPF) showed superior remineralization of subsurface enamel lesions in primary teeth than CPP-ACP 
without fluoride using energy dispersive $\mathrm{x}$-ray spectroscopy.

Therefore, there is a sound rationale for the addition of calcium ions to fluoride containing varnishes in an attempt to produce an increased retention of fluoride and calcium ions in the oral environment, leading to improved remineralization of early enamel lesions (6). Fluoride varnishes containing CPP-ACP are available as MI Varnish. It is composed of $5 \%$ sodium fluoride and $2 \%$ (Recaldent $^{\mathrm{TM} \text { ) }}$ (CPP-ACP) (12).

Cochrane et al (6) showed that the ion release profile of MI varnish was the most efficient, as it had high fluoride and calcium ion release. Shen et al (13) reported that MI varnish was superior to the other varnishes in inhibiting enamel demineralization in permanent teeth. The ion release profile of MI varnish was the most promising in literatures as it has high fluoride and calcium ion release. However, insufficient evidence is available to prove its efficacy on remineralization of caries-like lesions in primary teeth.

Therefore, the aim of the study was to evaluate the remineralization potential of $5 \%$ sodium fluoride containing CPP-ACP (MI varnish) on caries-like lesions in primary teeth compared to 5\% sodium fluoride (Prevident varnish). The null hypothesis was that there would be no significant differences in the mineral content of caries-like lesions of enamel between both varnishes.

\section{MATERIALS AND METHODS}

The current study was an experimental in vitro study that was performed in the departments of Pediatric Dentistry and Dental Public Health and Oral Biology, Faculty of Dentistry as well as the department of Geology, Faculty of Sciences, Alexandria University. The protocol of the study was approved by the Committee of Ethics, Faculty of Dentistry, Alexandria University, Egypt. The sample size was estimated using the assumptions alpha error $=5 \%$ and beta error $=5 \%$. The minimum required sample size per group using these assumptions was calculated using MedCalc to be 9 . This was increased to 12 per subgroup to make up for the errors in processing $(30 \%$ increase) $(14,15)$. The study sample was twenty-four maxillary anterior primary teeth that were collected from the outpatient dental clinic of Alexandria University hospital. The teeth were free from caries or cracks or any developmental defects.

\section{Creation of Caries-like Lesion:}

The twenty-four teeth were coated with nail varnish leaving $4 \times 4$ millimeter window on the labial surface. The window was standardized to produce a uniform surface area of exposed enamel. All the teeth were immersed in the demineralizing solution [2.2 $\mathrm{mM}$ calcium chloride $\left(\mathrm{CaCl}_{2}\right)$, $2.2 \mathrm{mM}$ potassium dihydrogen phosphate $\left(\mathrm{KH}_{2} \mathrm{PO}_{4}\right), 0.05 \mathrm{M}$ acetic acid $\left(\mathrm{CH}_{3} \mathrm{COOH}\right), 1 \mathrm{M}$ potassium hydroxide $(\mathrm{KOH})$ ( $\mathrm{pH} 4.4)]$ for 4 days to produce caries-like lesions (white spot lesion without cavitation). Then, the teeth were rinsed with deionized water and stored in artificial saliva $(16,17)$.

\section{Treatment Procedure}

The twenty-four teeth were randomly assigned in two treatment groups; group I (MI varnish) and group II (Prevident varnish). Each tooth was sectioned longitudinally in a labiolingual direction with a diamond disc through the center of the window into two equal halves; a mesial half and a distal one. One half was treated with the remineralizing agent and the other half remained untreated and served as its control. Each half was considered as a specimen (48 specimens). Subgroup I A: (n=12 specimens) $5 \%$ sodium fluoride with CPP-ACP (MI varnish GC Corp, U.S.A) was applied on specimens' labial surfaces (12). Subgroup II A: (n=12 specimens) 5\% sodium fluoride (Prevident varnish Colgate, U.S.A) was applied on specimens' labial surfaces. The 24 specimens were slightly dried with air and left in contact for four hours (18). The remineralizing tested varnish was removed from all specimens using a cotton swab soaked with acetone carefully to avoid damaging the enamel surface (19). All the specimens were rinsed with deionized water. For subgroup I B ( $\mathrm{n}=12$ specimens) and subgroup II B ( $\mathrm{n}=12$ specimens) were left untreated. All 48 specimens were stored in artificial saliva for 24 hours.

\section{The pH Cycling Model:}

Over a period of 10 days, continuous cycles of demineralization and remineralization were carried out for all the specimens. Each specimen was cycled in $5 \mathrm{ml}$ of each solution for 6 hours of demineralization and 18 hours of remineralization daily (20). Between each cycle, specimens were rinsed with deionized water. The demineralizing solution $(\mathrm{pH}=4.4)$ was previously described. The remineralizing solution $(\mathrm{pH}=7)$ consists of $[1.5 \mathrm{mM}$ calcium chloride $\left(\mathrm{CaCl}_{2}\right), 0.9 \mathrm{mM}$ sodium dihydrogen phosphate $\left(\mathrm{NaH}_{2} \mathrm{PO}_{4}\right), 0.15 \mathrm{M}$ potassium chloride (KCL)] (16).

Energy dispersive $x$-ray spectrometer (EDX) evaluation:

After $\mathrm{pH}$ cycling, the specimens were rinsed with deionized water and prepared for evaluation quantitatively using the EDX. Each specimen was mounted on a copper stub and analyzed using EDX (Jeol JSM-5300 Scanning Electron microscope, Faculty of Science, Alexandria University). Elemental content distribution of calcium (Ca) and phosphorus (P) elements weight \% of enamel was determined in the form of peaks on a graph with their corresponding readings. The $\mathrm{Ca}$ and $\mathrm{P}$ contents were converted into $\mathrm{Ca} / \mathrm{P}$ ratio for each group (21).

\section{STATISTICAL ANAL YSIS}

Data were coded and fed to statistical software IBM SPSS (Statistical Package for Social Science) version 20. The resultant variables were tested for normality using Kolmogorov-Smirnov test. Comparison between variables in the same group was carried out using Paired t test. Comparisons were carried out between the two studied groups using Mann-Whitney test. P value less than or equal to 0.05 was considered to be statistically significant.

\section{RESULTS}

The mean Ca content and $\mathrm{Ca} / \mathrm{P}$ ratio of MI varnish treated specimens (subgroup I A) was statistically significantly higher than untreated specimens (subgroup I B) at $(\mathrm{P}<0.0001)$. The mean $\mathrm{P}$ content of subgroup I A was significantly lower than subgroup I B at $(\mathrm{P}<0.0001)$, Table (1). 
Table 1: Mean Ca, $\mathrm{P}$ contents and $\mathrm{Ca} / \mathrm{P}$ ratio of group I (MI varnish) between subgroup A (test) and B (control).

\begin{tabular}{|c|l|c|c|c|}
\hline \multirow{2}{*}{ Elemental content } & \multicolumn{2}{|c|}{ Group I(MI varnish) } & \multirow{2}{*}{} \\
\cline { 3 - 4 } & $\begin{array}{l}\text { Subgroup } \\
\text { IA (Test) }\end{array}$ & $\begin{array}{c}\text { Subgroup } \\
\text { IB } \\
\text { (Control) }\end{array}$ & \multirow{2}{*}{ Paired t (P) } \\
\hline Ca & $\begin{array}{l}\text { Mean } \pm \\
\text { SD }\end{array}$ & $70.68 \pm 3.40$ & $64.68 \pm 1.86$ & $7.13(<0.0001)^{*}$ \\
\hline P & $\begin{array}{l}\text { Mean } \pm \\
\text { SD }\end{array}$ & $29.3 \pm 3.39$ & $35.28 \pm 1.85$ & $7.27(<0.0001)^{*}$ \\
\hline $\begin{array}{c}\text { Ca/ P } \\
\text { ratio }\end{array}$ & $\begin{array}{l}\text { Mean } \pm \\
\text { SD }\end{array}$ & $2.45 \pm 0.41$ & $1.84 \pm 0.15$ & $5.96(<0.0001)^{*}$ \\
\hline
\end{tabular}

$* \mathrm{P}<0.05$ (significant)

The mean Ca content and $\mathrm{Ca} / \mathrm{P}$ ratio of Prevident varnish treated specimens (subgroup IIA) was statistically significantly higher than untreated specimens (subgroup II $\mathrm{B})$ at $(\mathrm{P}<0.0001)$. The mean $\mathrm{P}$ content of subgroup II A was significantly lower than subgroup II $\mathrm{B}$ at $(\mathrm{P}<0.0001)$, Table (2).

Table 2: Mean $\mathrm{Ca}, \mathrm{P}$ contents and $\mathrm{Ca} / \mathrm{P}$ ratio of group II (Prevident varnish) between subgroup A (test) and $\mathrm{B}$ (control).

\begin{tabular}{|c|c|c|c|c|}
\hline \multirow{2}{*}{\multicolumn{2}{|c|}{$\begin{array}{c}\text { Elemental } \\
\text { content }\end{array}$}} & \multicolumn{2}{|c|}{$\begin{array}{c}\text { Group II (Prevident } \\
\text { varnish) }\end{array}$} & \multirow{2}{*}{ Paired t (P) } \\
\hline & & Subgroup & $\begin{array}{c}\text { Subgroup } \\
\text { IIB }\end{array}$ & \\
\hline Ca & $\begin{array}{l}\text { Mean } \pm \\
\text { SD }\end{array}$ & $62.50 \pm 2.51$ & $60.59 \pm 2.38$ & $5.36(<0.0001)^{*}$ \\
\hline $\mathbf{P}$ & $\begin{array}{l}\text { Mean } \pm \\
\text { SD } \\
\end{array}$ & $37.52 \pm 2.49$ & $39.42 \pm 2.40$ & $5.30(<0.0001)^{*}$ \\
\hline $\begin{array}{l}\mathrm{Ca} / \mathrm{P} \\
\text { ratio }\end{array}$ & $\begin{array}{l}\text { Mean } \pm \\
\text { SD } \\
\end{array}$ & $1.68 \pm 0.18$ & $1.55 \pm 0.16$ & $5.56(<0.0001)^{*}$ \\
\hline
\end{tabular}

$* \mathrm{P}<0.05$ (significant)

The median percent change of $\mathrm{Ca} / \mathrm{P}$ ratio of group I (MI varnish) was statistically significantly higher than median percent change of $\mathrm{Ca} / \mathrm{P}$ ratio of group II (Prevident varnish) at $\mathrm{P}<0.0001$, Table (3).

Table 3: Median\% change of $\mathrm{Ca} / \mathrm{P}$ ratio between group I and II.

\begin{tabular}{|c|c|c|c|}
\hline $\begin{array}{l}\% \text { Change } \\
\text { Ca/P ratio }\end{array}$ & $\begin{array}{l}\text { Group I } \\
\text { (MI } \\
\text { varnish) }\end{array}$ & $\begin{array}{c}\text { Group II } \\
\text { (Prevident } \\
\text { varnish) }\end{array}$ & $\begin{array}{c}\text { Z of Mann- } \\
\text { Whitney test } \\
\text { (P) }\end{array}$ \\
\hline Minimum & 11.19 & 0 & \multirow{3}{*}{$\begin{array}{c}3.70 \\
<0.0001 *\end{array}$} \\
\hline Maximum & 70.24 & 15.49 & \\
\hline Median & 28.96 & 7.40 & \\
\hline
\end{tabular}

The results of the present study rejected the proposed null hypothesis that indicated no significant differences in the mineral content of treated caries-like lesions of enamel between both varnishes.

In the current study, MI varnish treated specimens showed significant higher mean $\mathrm{Ca}$ content, $\mathrm{Ca} / \mathrm{P}$ ratio than untreated (control) specimens when evaluated by EDX. The EDX quantitatively measured the levels of calcium, phosphorus elements in enamel representing an indication of the rate of remineralization and denoting lesion changes (21). The results are consistent with the data presented by Savas et al (22) who reported that $\mathrm{Ca} / \mathrm{P}$ ratio was significantly higher in the remineralization phase of MI varnish compared to those of the demineralized surfaces in bovine incisor teeth. According to Reynolds (5) CPP stabilize nanoclusters of ACP preventing their growth into the critical size for phase transformations. This ensures that the ions remain bioavailable to diffuse into mineral deficient lesions to allow for remineralization of demineralized crystals.

Regarding the Prevident varnish, the treated specimens showed significant higher mean $\mathrm{Ca}$ content, $\mathrm{Ca} / \mathrm{P}$ ratio than the untreated (control) specimens. These results were in accordance with De Carvalho Filho (21). Hicks et al (23) showed that fluoride application causes the chemical changes in the main component of the enamel hydroxyapatite as calcium fluoride deposition thus inducing chemical stability and remineralization. Oliveira and Mansur (24) revealed that applied fluoride varnish incorporates into enamel crystals, thereby forming a fluorapatite like mineral, which improves the remineralization ability of the enamel.

When comparing the MI varnish with the Prevident varnish, the MI varnish treated specimens had a significantly higher median percent change of $\mathrm{Ca} / \mathrm{P}$ ratio. This may be due to calcium and phosphorus available in high concentrations in terms of composition of MI varnish indicating better remineralization capacity. This ensures that the ions remain bioavailable to diffuse into mineral deficient lesions to allow for remineralization of demineralized crystals. This finding is in accordance with Kariya et al (25) who demonstrated that CPP-ACP interacts with fluoride ions to produce an additive remineralization effect through formation of stabilized amorphous calcium fluoride phosphate phase. The remineralized minerals show improved acid resistance without being further demineralized. Moreover, Lippert et al (26) concluded that MI varnish showed an almost constant fluoride release for 6 hours while, the remaining fluoride varnishes including Prevident varnish exhibited very low fluoride release overall with the majority of fluoride being released within the first 2 hours. Our results are in agreement with Cochrane et al (6) that determined the ion release by ion chromatography from different fluoride containing varnishes. It was concluded that MI Varnish was the most efficient as it had high fluoride and calcium ion release. Furthermore, Shen et al (13) evaluated the ability of different fluoride containing varnishes to inhibit enamel demineralization and it was concluded that MI Varnish was superior to the other varnishes in protecting against enamel demineralization in permanent teeth.

A possible limitation of the present study was that the controlled environment of the study lacks some of the natural oral condition. The $\mathrm{pH}$ cycling model didn't entirely simulate the complex oral conditions where the $\mathrm{pH}$ fluctuates frequently. The attained levels depend upon the individual's eating habits, oral hygiene practices, fluoride usage and the composition and the quality of saliva and plaque.

Within the limita ion of the study, both MI varnish and Prevident varnish were effective agents for remineralization of caries-like lesions. Fluoride varnish containing CPPACP (MI varnish) was shown to produce significant acid resistant remineralization relative to sodium fluoride varnish (Prevident varnish) when evaluated by means of elemental analysis. Further studies should be conducted to evaluate clinically the remineralization efficiency of using 
MI varnish in high risk children with active caries-like lesions.

\section{CONCLUSIONS}

Based on the results of this study, it is concluded that:

1. Using Elemental analysis, MI and Prevident varnishes showed significant remineralization of caries-like lesions in enamel.

2. MI varnish showed significant acid resistant remineralization.

\section{CONFLICT OF INTEREST}

The authors declare that they have no conflict of interest.

\section{REFERENCES}

1. Cury JA, Tenuta LM. Enamel remineralization controlling the caries disease or treating early carious lesions. Braz Oral Res. 2009; 23: 23-30.

2. Cochrane NJ, Cai F, Huq NL, Burrow MF, Reynolds EC. New Approaches to enhanced remineralization of tooth enamel. J Dent Res. 2010; 89: 1187-97.

3. Schemhron BR, Wood GD. Comparison of fluoride uptake into tooth enamel from two fluoride varnishes containing different calcium fluoride sources. J Clin Dent. 2011; 22; 51-4.

4. Marinho VCC, Worthington HV, Walsh T, Clarkson JE. Fluoride varnishes for preventing dental caries in children and adolescents. Cochrane Database Syst Rev. 2013; 7; 8-18.

5. Reynolds EC. Calcium phosphate-based remineralization systems: scientific evidence. Aust Dent J. 2008; 53: 26873.

6. Cochrane NJ, Shen P, Yuan Y, Reynolds EC. Ion release from calcium and fluoride containing dental varnishes. Aust Dent J. 2014; 59: 100-5.

7. Seppa L. Fluoride varnishes in caries prevention. Med Princ Pract. 2004;13: 307-11.

8. Pradeep K, Prasanna RK. Remineralizing agents in the non-invasive treatment of early carious lesions. Int J Dent Case Reports. 2011; 1: 73-84.

9. Llena C, Forner L, Baca P. Anticariogenicity of casein phophopeptide-amorphous calcium phosphate: a review of the literature. J Contemp Dent Pract. 2009; 10: 1-9.

10. Gupta R, Prakash V. CPP-ACP complex as a new adjunctive agent for remineralisation: a review. Oral Health Prev Dent. 2011; 9:151-65.

11.Heikal M. The effect of casein phosphopeptide amorphous calcium phosphate on remineralization of caries-like lesions in primary teeth. Master thesis. Faculty of Dentistry, Alexandria University; 2012.

12. GC Company America. Instructions for use of MI varnish. Available at: http://www.gcamerica.com/products/preventive/MI_Varni sh/. Accessed on March 2015.

13. Shen P, Bagheri R, Walker GD, Yuan Y, Stanton DP, Reynolds C, et al. Effect of calcium phosphate addition to fluoride containing dental varnishes on enamel demineralization. Aust Dent J. 2016; 61: 357-65.

14. Rirattanapong P, Vongsavan K, Saengsirinavin C, Pornmahala T. Effect of fluoride varnishes containing tricalcium phosphate sources remineralization of initial primary enamel lesions. Southeast Asian J Trop Med Public Health. 2014; 45: 499-502.
15. Yoshaskam A, Namratha LP, Gaurav P, Thajuraj PK. The effect of CCP-ACP on remineralization of artificial caries lesions: an in vitro study. Indian J Multidiscip Dent. 2011; 2: 366-77.

16.ten Cate JM, Duijesters PPE. Alternating demineralization and remineralization of artificial enamel lesions. Caries Res. 1982; 16: 201-10.

17. Kumar VLN, Itthagarun A, King NM. The effect of casein phosphopeptide-amorphous calcium phosphate on remineralization of artificial caries-like lesions: an in vitro study. Aust Dent J. 2008; 53: 34-40.

18. Colgate ${ }^{\circledR}$ company Prevident ${ }^{\circledR}$ Varnish. Instructions for use for prevident varnish. Available at: http://www.colgateprofessional.com/products/colgateprevident-varnish-rx-only/information. Accessed on March 2015.

19. Cardoso CA, de Castilho AR, Salomão PM, Costa EN, Magalhães AC, Buzalaf MA. Effect of xylitol varnishes on remineralization of artificial enamel caries lesions in vitro. J Dent. 2014; 42: 1495-501.

20. Itthagarun A, Wei SH, Wefel JS. The effect of different commercial dentifrices on enamel lesion progression: an in vitro pH-cycling study. Int Dent J. 2000; 50: 21-8.

21. De Carvalho Filho AC, Sanches RP, Martin AA, Do Espírito Santo AM, Soares LE. Energy Dispersive XRay Spectrometry Study of the Protective Effects of Fluoride Varnish and Gel on Enamel Erosion. Microsc Res Tech. 2011; 74: 839-44.

22. Savas S, Kavrik F, Kucukyilmaz E. Evaluation of the remineralization capacity of CPP-ACP containing fluoride varnish by different quantitative methods. J Appl Oral Sci. 2016; 24: 198-203.

23. Hicks J, Garcia-Godoy F, Flaitz C. Biological factors in dental caries: role of remineralization and fluoride in the dynamic process of demineralization and remineralization (part 3). J Clin Pediatr Dent. 2004; 28: 203-14.

24. Oliveira M, Mansur HS. Synthetic tooth enamel: SEM characterization of a fluoride hydroxyapatite coating for dentistry application. Master Res. 2007; 10: 115-8.

25. Kariya S, Sato T, Sakaguchi Y, Yoshii E. Fluoride effect on acid resistance capacity of CPP-ACP containing material. Abstract 2045. $82^{\text {nd }}$ General Session of the IADR 2004, Honolulu, Hawaii. Available at: http://www.the-ozone.cc/research/abstracts/ab147.pdf. Accessed on November 2016.

26. Lippert F, Hara AT, Martinez-Mier EA, Zero DT. Laboratory investigations into the potential anticaries efficacy of fluoride varnishes. Pediatr Dent. 2014; 36: 291-5. 